\title{
Post-truth, propaganda and the transformation of the spiral of silence
}

This paper is to be published in the Journal of Media \& Cultural Politics CIntellect

Poulakidakos, S., Veneti, A. and Frangonikolopoulos, C., 2018. Post-truth, propaganda and the transformation of the spiral of silence. International Journal of Media and Cultural Politics, 14 (3)

\begin{abstract}
In 2016, post-truth was named word of the year. Since then a handful of texts have sought to further describe and explore the notion, moving beyond the initial definition given by the Oxford Dictionary. This paper rejects the term 'post-truth', in favor of propaganda; since post-truth tends to be utilised as an evaluative term of contemporary political public discourse, as articulated by specific politicians, predominantly through social media. Taking the field of information management as its starting point, our approach underlines the diachronic character of persuasion efforts through information management, understood as propaganda in the public sphere. As a notion, propaganda, in contrast to post-truth, encapsulates both the diachronic character of information management in the public sphere and the ground-breaking transformation of the process of personal opinion expression, initially described by the spiral of silence model, through the emergence of new interactive media.
\end{abstract}

\section{The role of information management in modern societies}

Information is a reference point for contemporary societies (Poster 1990: 7). In quantitative (technical) terms, information constitutes the "quantitative measure of communication exchange". Thus information is whatever can be encoded and transmitted through a channel connecting a sender and a receiver, regardless of its content (Roszak 1986: 11; Stonier in Webster 2006: 26). In qualitative (social) terms, information is "one or more statements and/or facts perceived by a human being and having a certain value for the receiver" (Cox 2013: 61). Information is produced as the transmittable form of a message, while at the same time, the values contained in this message shape the information in social/qualitative terms (Losee 1988).

Information is at the epicenter of social structure (Bell 1978; Schiller 1984; Poster 1990; Castells 2004), since it conquers time and space; initially through its, mainly unilateral/analogue, broadcast and more recently through its -multilateral/interactivedigital dissemination (Terranova 2004), thus constituting a fundamental ingredient of contemporary political, cultural and financial activities. Contemporary Western societies are 'information societies', since their information structures have become the basic sources of productivity and power. Instead of the commercialisation of information, we now encounter the informationalisation of commercialisation (Demertzis 2017:14). This is the result of the orientation of financial activity with respect to immaterial symbolic commodities (Lash \& Urry 1996: 204-210) and new technological achievements (such as digital information networks) (Gleick 2011).

The most prevalent cultural effect of the network society is the ability that everyone potentially now has for customised interaction and access to information production and 
dissemination (Webster 2006; Tunstall 2008). Key players in this information frenzy are the mass media, whose values and ideology affect the public sphere (Fowler 2003). The mass media focus on specific issues and cultivate specific patterns of social behavior (Luhmann 2000: 76-88). Following social constructivist accounts (Demertzis 2002; Christakis 2016:11), mass media have been major actors in the formation of social reality (Thompson 1999: 7; Burr 2006). As Postman (1985: 14) suggests: “We don't see reality the way it is, but the way our languages are. Our languages are the media. The media are our metaphors. Our metaphors create the content of our culture."

Through the evolution of audiovisual electronic media (radio, television) "the conscience industry, hence the public opinion formation industry, has become the pacemaker of the socio-financial evolution of late/post-industrial societies" (Enzensberger 1981:9). Information management is a basic characteristic of contemporary societies; one that defines the elaboration and dissemination of specific information mainly from professionals of communication management aimed at influencing public opinion in terms of politics, consumption and culture, in specific ways (Kumar 2006; Webster 2006: 190).

Especially since the outbreak of WWI (the first "total war"), political and financial elites have been engaged in constant processes of negotiation with the mass media, in order to control it and ensure that the media will promote their interests (Cull, Culbert \& Welch 2003). Due to the prevalence of the mass media in the production and dissemination of information (e.g. advertisements, public relations, politics, business) (Webster 2006: 168), information is not merely the event that takes place outside of the media that is simply reported by the media, but the event modified and (re)presented by the media (Mitu and Poulakidakos 2016).

Following such arguments, we conceptualise information management as a vital part of perception management. Perception management includes attempts to influence public opinion to align with specific interests (Siegel 2005). Understood in this manner and in these contexts, information becomes a specific means of (re)orienting power structures, a means for (re)constructing reality (Terranova 2004: 37). In operational terms, publicly disseminated information that serves to influence others with respect to their beliefs and/or actions constitutes propaganda (Auerbach and Castronovo 2013: 6), though it is worth bearing in mind that not everything that is widely disseminated in public lends itself to such analysis as a piece of propaganda (Auerbach and Castronovo 2013: 5)

\section{Describing propaganda}

Propaganda is defined through the application of four interdependent principles: the attempt to influence people's minds and behavior; the efficient use of mass media; the understanding of the psychological condition of the intended/desired audience; and the exploitation of socially established behavioral patterns (Bernays 1928; Jowett \& O' Donnell 2015). Propaganda makes (intense) use of emotions, drawing on sentimental factors, and seeks to persuade in order to serve the aims of the propagandist through disseminating a certain ideology or doctrine (Taylor 2004; Marková 2008; Poulakidakos \& Armenakis 2014; Jowett \& O' Donnell 2015). In addition, propaganda is a phenomenon adaptive to different social contexts (Jowett \& O' Donnell, 2015: 391); it is adaptive to the media it utilises, trying to take advantage of their structure and operational culture to serve its purposes (Miotto 1953; Ellul 1973). Propaganda has been assisted in its development by the evolution of the 
media (The Economist 2016). The media form propaganda, whilst propaganda forms the media and modern societies (Pleios 2005).

In the contexts outlined above, it seems important that we should aim to recognise propaganda for what it actually is: a communication strategy (Auerbach and Castronovo 2013; Jowett and O' Donnell 2015: 389) and something that forms a part of our everyday life (Taylor 2003: 321). The interests of those implementing propagandistic strategies may align or be at odds with our own. When they align, we tend not to label this as propaganda; rather they serve to buttress our value system, our truth. In this vein, Taylor (2003:321) argues that "whether we will call a piece of information propaganda or not, depends on the side we are" and similarly Bernays (cited in Sproule 1997: 57) asserts that "the information we believe in is education; the information we don't believe in is propaganda."

Initially, the Catholic Church used the term propaganda in 1622 to denote the promotion of specific ideas (Severin \& Tankard 2000). Later on, because of its massive implementation before and during WWI, its use by authoritarian regimes (e.g. the Nazis) and the prevalence of the American school of thought with respect to its description and definition, propaganda became closely related with dishonesty and as such acquired heavily negative connotations. Lies, deceit, manipulation, mind control and brainwashing have been long considered synonyms for propaganda (Levinson 1999: 39; Jowett \& O' Donnell 2015). In order to focus on the communicative/functional aspect of propaganda (Auerbach and Castronovo 2013) and thus to approach it as a method of public communication, we define it as a deliberate, mainly political, communication strategy, exercised through the dissemination of managed information via the mass media, aimed at influencing others with respect to their beliefs and/or actions.

\section{Propaganda and the media in the different periods of modernity ${ }^{1}$}

During the financial, political and cultural contexts of early modernity, when coercion was the prevalent force for the implementation of the will of the divine right power and major financial interests, propaganda had a restricted role, being utilised mainly during wartime (Taylor 2003: 87-96), implemented through the dissemination of print media (e.g. leaflets, early forms of Press). During that time, propaganda had a complementary role to coercion policies, since the use of (military) force against external and internal enemies of the established political and financial regimes was common practice (Thompson 1999: 91-92). With the emergence of liberal democracy, the utilisation of propaganda practices has vastly increased (Zollman 2017:1). Since modernity, the (political) elites have needed to utilise propaganda to legitimise their policies, with respect to a more politicised audience (Pleios 2011: 95). The modernisation of politics, through the generalisation of political participation (Demertzis 2001; Christakis 2016:25) has contributed to the generalisation of propaganda.

During modernity, an array of new media came to surface. Along with the Press, the emergence of cinema, radio and television (audiovisual media) gave new impetus to the application of propaganda across all different aspects of social activity. Cinema was widely used to propagate national, social and financial messages (McQuail 2010). Radio was

\footnotetext{
${ }^{1}$ As a socio-historical condition, modernity engulfs internal evolutions and discontinuities. The division of the different periods of modernity and late/post-modernity (early modernity, modernity, late/post-modernity) is subjected to wide debate among scholars. Hence, there are different periodisations of the post-traditional, postmedieval, period of modernity (see Harvey 1990; Hall and Gieben 1992).
} 
similarly used for propagandistic purposes. Radio and related technological breakthroughs formed a new sphere of culture and entertainment, and thus practices and models of propaganda (Pleios 2005). The emergence of television and the gradual creation of a wide variety of entertainment and news programmes led to the radical development of new propagandistic strategies (Ramonet 2001: 142-143; Curtis 2003: 379; Keyes 2004: 176-177; McQuail in Curran-Gurevitch 2011).

The audiovisual media (cinema, radio, television) of the $20^{\text {th }}$ century disseminated information in a unilateral way -their discourse was an "unanswered" one (Poster 1995: 17), a "language of command" (Adorno and Horkheimer 1986). Their "grammar" enabled political and financial elites to control the content (Hanretty 2011: 46, 15-17), form the necessary conditions for the exercise of propaganda -aimed at imposing a top-down control of the public sphere (Habermas 1984: 372)- and widen the reach of propaganda messages (Jowett \& O' Donnell, 2015: 391).

Towards the end of the $20^{\text {th }}$ century, a technological revolution occurred with the communication technologies as its epicenter (Castells 2000: 1). The internet is the epitome of this information revolution. The new types of information flow and their personalised reception (Jowett \& O' Donnell, 2015: 391) has influenced the rationale for propaganda within this new informational space. The disaggregation of audiences alongside the complexity as to how content circulates via digital media has created new communication conditions (Nerone 2015). In the multifaceted web universe, propagandistic information cannot totally undermine opposing messages (McNair 2006: 9). In contrast to the "propaganda-exclusive" media of modernity, the late-modern internet is a "propagandainclusive" medium. In this sense, it encompasses the production and dissemination of multiple (propagandistic) messages/opinions, within a single but not homogeneous communication space (Soules 2015: 220), from various actors though not necessarily through a hierarchical, top-down rationale (from the elites to the people).

In the contemporary digital world, the internet's interactive character and the increased expression of personal subjective opinions, lead to an increase in the level of subjective interpretation concerning the financial, political and cultural aspects of society (The Economist 2016; Uberti 2017; Martin 2017), a tendency towards a "democratization" of communication (Bauman 1997; Kumar 2005). To use Niklas Luhmann's sociological terminology, society and internet technology systems are 'structurally coupled' and 'interpenetrate each other' reflexively, in this mutual dynamic process of co-construction and co-evolution (Demertzis and Tsekeris 2018:1).

The participation of multiple -literally millions of- channels, websites, and social media feeds (Harsin, 2014) in the online communication and information "ecology", in which any single user can openly express her/his own opinion on something (Gillmor 2004, Martin 2017) and send it to hundreds, thousands, even millions of others almost instantaneously (Jowett \& O' Donnell, 2015: 394), facilitates propaganda (Martin 2017).

Within this communication context, managed information, especially that intended to deceive, is one of the most prominent problematic issues (Weber 1995: 105; The Economist 2016; Uberti 2017). The difficulties of verifying information sources, alongside the widespread expression of personal opinions, suggests a new propaganda model, that is expressed mainly through personal opinions, which seeks to spread as widely as possible (Poulakidakos 2014). Within the contexts, definitions and rationales outlined above, we are 
going to examine the notion of "post-truth" and suggest that it actually constitutes propaganda, since it combines diachronically exercised -by various actors- persuasion efforts in the public sphere and the adaptation of these efforts to the particular characteristics of the contemporary communication context.

\section{Post-truth or propaganda?}

The use of the term "post-truth" increased by around 2,000\% in 2016, compared to the year before. This spike in the usage of the term took place "in the context of the EU referendum in the United Kingdom and the presidential election in the United States" (Flood 2016; McComiskey 2017: 3; Speed and Mannion 2017). Since then, it has been closely associated with specific political figures, such as Donald Trump, Nigel Farage, Recep Erdogan, and Vladimir Putin (Stratford 2017), signifying a rather negative trend in politics. This sudden and dramatic increase in the articulation of the term in the public sphere, as well as its strongly negative connotations (Rabin-Havt and Media Matters for America 2016) are reminiscent of the similar outbreak of discussion and predominantly negative approaches concerning propaganda in the aftermath of WWI (Demertzis 2001: 28; Nimmo and Sanders 1981).

'Post-truth' is defined by the Oxford dictionary as an adjective "relating to, or denoting circumstances in which objective facts are less influential in shaping public opinion than appeals to emotion and personal belief" (Flood 2016, Hodges 2017, McComiskey 2017: 5). Although the term "post-truth" may have a recent pedigree, there is nothing at all new about populist discourse (Powell 2017) misinformation and even outright lies (Ball 2017), all of which feature as constituent "parts" of propagandistic discourse. If there is anything new with respect to this issue, it is the exponentially growing influence of the internet, more specifically of social media and the World Wide Web (Rowe and Alexander 2017: 179).

With respect to its journalistic dimension, post-truth describes articles which constitute an assemblage of facts, information, rumors, statements, rumors of statements, and officials' estimations and predictions of the future. Hence, post-truth signifies the existence of various degrees of truth (Triandafyllou 2017, Berghel 2017) that emerge and are shaped either by the intentions of journalists or by the institutional "pressure" exercised on journalists by media organisations (Zollman 2017). Similarly, in post-truth politics, truth is of secondary importance. Feelings, not facts, are what matter in this sort of campaigning (The Economist 2016). In the post-truth world, language becomes purely strategic, without reference to anything other than itself (McComiskey 2017: 8); ethos and pathos function at the expense of logos, and become effective sources of arguments, since logos is actually denigrated (McComiskey 2017: 10-11, 20). This post-truth approach is directly equivalent to the approaches of propaganda. It describes an attempt to strategically influence public opinion in favor of that desired by the producer and disseminator of managed information. Doing so through the use of specific discursive practices (opinions over facts, emotions over rationalism, half-truth or even lies - e.g. fake news (Harsin 2015; Oremus 2016; Hofseth 2017; Berghel 2017)) instead of research, rumors instead of cross-checked information.

These practices are not at all new in the articulation of public discourse and the diachronic attempts of propagandists to influence public opinion (Keyes 2004; Soules 2015: 208-210; Corner 2017: 1100; Lilleker 2017; Rowe and Alexander 2017). As illustrated by the previous theoretical discussion, propaganda - the attempt to influence the opinion and 
behavior of the public, through the management of publicly disseminated information - is a strategy used by several actors (political or not) since ancient times and in a systematic way, at least since the early $20^{\text {th }}$ century (Taylor 2003).

Propaganda is closely connected to the century-long development of professional political communication which, as a response to the modernisation of politics, has, in both democratic and totalitarian regimes, conceived of the mass of citizens as risks to be managed (Keyes 2004; Harsin 2006; Harsin 2015: 331). As with propaganda, which due to its historical use by totalitarian regimes acquired negative connotations, the term post-truth incorporates an inherent negativism, due to its emergence in the public sphere following the propagandistic campaigns of Trump and those political representatives that campaigned for Brexit. Hence, the very use of the term post-truth - as with that of its predecessor, propaganda- has been propagandistic in nature. This foregrounds the need to always bear in mind that the term propaganda and its contemporary equivalent, post-truth, denote a struggle between ideologically different sides for the hearts and minds of the people (Snow and Taylor 2009).

These similarities, discussed above, as to the definitions and descriptions of "post-truth" and "propaganda" lead us to the conclusion that " in its predominantly political implementation, when utilised in order to influence specific social groups, "post-truth", , is actually propaganda, for two main reasons. Firstly, the term "post-truth" signifies a distantiation between the current public communication contexts and the truth, in both quantitative and qualitative terms, while also implying at the same time, that in past periods or social contexts truth was the prevalent or even the only trend in public communication (Powell 2017: 724). This contradicts scientific and real-life evidence (some of which research has been briefly presented in this paper) that the broadcast and dissemination of managed information in the public sphere has been a widely used method of influence, exercised with different qualitative and quantitative parameters- diachronically and systematically, at least since early $20^{\text {th }}$ century. Secondly, the "democratisation" of communication, especially with the emergence of social media, has enabled every internet user to express his or her own opinion on any given issue. This quantitative pluralism makes it possible for the information circulating the web to be committed to a wide range of political ideologies, religions and cults, conspiracy theories, art movements etc (Pleios 2011:156). Within such a communication context, propaganda functions not only as a top-down procedure, a communication strategy directed from the elites to the masses, but rather as a mix of topdown and grassroots (between users) dissemination of managed or personal-subjective information (Auerbach and Castronovo 2013:9), while still having as its central aim to influence the perceptions of various publics on certain issues of public interest. This happens due to the fact that people tend both to believe that which already fits with their ideological orientation (Triandafyllou 2017), and to share their opinions either with people they agree with (McComiskey 2017), or with people they seek to influence.

In other words, propaganda, as well as operating through traditional unilateral communication channels, is nowadays exercised within the digital, decentralised, not exclusively hierarchical regarding production and dissemination of information context of the internet, especially that of social media. In this respect, the social media communication context actually operationalises more so than ever before, Philip Taylor's claim that "we are 
all in fact propagandists to varying degrees, just as we are all victims of propaganda" (Taylor 2003:2).

This emerging "democratisation" of communication, alongside the increased expression of personal subjective opinions, has influenced both inter-personal and mass communication. It has transformed possibilities such that each individual can decide to openly express her/his opinion on a given issue. In what follows below the transformation of Noell-Numann's (1974) theory of the spiral of silence, which explores the reasons behind public participation and non-participation in mass communication, brought about in significant part by the interactive communication context of the internet and the social media, is explored.

\section{The transformation of the spiral of silence}

The dissemination of information through online media has changed the way people obtain information nowadays. Traditional journalism used to be the only source of information accessible to a large audience, but new sources have emerged as anyone can now provide information in a digital (quasi) public space. User-generated content (UGC) in the shape of blogs or on social network sites (SNS), as well as content contributed by actors deeply dependent on the wide dissemination of their messages (e.g. political parties, nongovernmental organisations, social institutions, companies), complements mass media content in both online media outlets and in legacy media such as print and electronic media (Porten-Cheé and Eilders 2014: 143; Fox and Warber 2015; Zerbak and Fawzi 2016). The quantitative expansion of content is also related to an increase in opinion diversity, since every additional user-generated item may present a unique perspective not yet provided or addressed by the mass media (Gerhards and Schäfer 2010; Dylko and McCluskey 2012). The more easily people can put together distinct media diets through such opportunities, the more likely they are to find opinions that match their own perspectives, and they may even lose touch with the issues and opinions being discussed by society at large (Porten-Cheé and Eilders 2014: 143).

The emergence of the internet has brought about an interactive, non-linear, nonpyramidal (non-hierarchical) communication process. The "atomised" and "democratised" (in quantitative terms) internet communication context and the multiplicity of information media has resulted in an increase in the expression of personal, subjective opinions and interpretations of reality. Opinion expression is central to social interactions on social media: certain attributes of a post for instance, can encourage or discourage further participation and expressions of opinion (Pang et al. 2016: 898).

The causal relation between exposure to particular media content and opinion expression in public is the theoretical backbone of the concept of the spiral of silence, put forward by Noelle-Neumann (1974) in her theory of public opinion. According to the spiral of silence, the perception of the opinion climate guides people's communicative behavior in the public sphere (Noelle-Neumann 1974; Miyata, Yamamoto and Ogawa 2015; Luo et al. 2016; Liu, Rui and Cui 2017). The spiral of silence theory proposes that individuals are likely to speak out in public if they perceive themselves to be in the present or future majority on an issue. In a complementary fashion, when they perceive themselves to belong to the minority, people - afraid of being socially isolated - are much less likely to express their 
opinion openly. In order to assess the climate of opinion, people closely monitor their social environment via the mass media. Since the opinion perceived as a majority opinion is expressed in public and the opinion perceived as a minority opinion is not expressed in public, a spiraling process is initiated, in which the alleged majority opinion gains ground and the alleged minority opinion loses ground (Gearhat and Zhang 2014; Fox and Warber 2015; Soffer and Gordoni 2018). The spiral of silence mechanism explains how micro-level individual behavior, such as speaking out in public under particular conditions, might spill over to the macro-level of public opinion formation (Porten-Cheé and Eilders 2014: 144).

The spiral of silence and the "democratisation" of communication do not refer to the same communication "level". The former focuses on an internal decision making process conducted by a person before deciding whether she/he is going to openly express her opinion, while the latter describes a media context containing a multiplicity of openly expressed opinions. These two "dimensions", though, are closely connected, since mass media content has an inevitable effect on people's perception of the opinion climate (Porten-Cheé and Eilders 2014: 144).

Especially in the personalised communication context of social media, where the personal is interwoven with the public more than ever before, an individual's assessment as to whether she/he should express her/his opinion in public is more important than ever. On the one hand, we encounter a constant even instant application of the internal decisionmaking procedure of the spiral of silence model. However, on the other hand, due to the wide variety of interests and opinions publicly expressed, the individual usually does not feel the same level of "oppression" by the dominant majority opinion, as she/he will probably find other people with similar beliefs, opinions and interpretations to their own. Thus, each individual undertakes the decision-making procedure described by the spiral of silence, without - in most cases - having the same level of fear of possible social exclusion, the main negative consequence described by the spiral of silence. The opinion-inclusive ecology of the internet and social media diminish the fear of social exclusion and thus serves to release the self-expressing potential of individuals online.

Thus, with respect to more (quantitatively) pluralistic communication environments, where a greater variety of publicly expressed opinions can be found, the spiral of silence dynamic is "reduced". In more "traditional", centrally controlled, communication environments with one-way, top-down information broadcast, a lesser range of opinions, sometimes limited to a single opinion, are available in the public sphere, thus negatively influencing the likely public expression of a wider range of opinion. In this way, propaganda, especially online, is considerably influenced by the "democratisation" of communication, serving to diminish the censoring effect of the spiral of silence.

Among the most characteristic examples of this "weakening" of the dynamics of the spiral of silence, within the interactive communication environment, is the open discussion and wide dissemination of conspiracy theories. Conspiracy theories are appealing because they offer simple explanations for complex phenomena -especially in times of social unrest (van Prooijen and Douglas 2017)-, or because they let people believe they are in possession of secret knowledge that the powerful wish to suppress (The Data Team 2017). Conspiracy theories are not restricted to the online world (van Prooijen and Douglas 2017) and their online dissemination is as old as the internet itself: the crash of TWA Flight 800 in 1996 
sparked numerous alternative accounts of the plane's demise and the attack on the World Trade Center in 2001 marked a milestone in terms of the development and widespread dissemination of unproven rumors with respect to speculation as to the perpetrators of the attack. More recently, the chemtrails theory, the anti-vaccination movement and the flatearth theory, due to their expansive discussion in online communities (Bratich 2004; Clarke 2007; The Data Team 2017; Pappas 2018; Yenko 2018), have even hit the mainstream media, and in several cases have been transformed into offline activities ${ }^{2}$.

It is also the case that, the internet and more specifically social media, has repeatedly served as a means for organising and communicating with respect to grass-roots social movements, which oppose mainstream elite political discourse. During the uprisings across the Middle-East and North Africa (MENA) in 2011, the role played by social media can be viewed in terms of both a battleground for information freedom and freedom of expression and as a coordinating mechanism for political mobilisation. The use of social media can facilitate efficiencies in internal organisation, or else displace the need for formal structures of coordination altogether (Axford 2018: 21). Of the online activism that took place across MENA countries in 2011, it is suggested that the use of social media greatly increased the ability of social movements and protesters to coordinate across borders and to link up with other organisations (Axford 2011).

These examples, provided with respect to conspiracy theories and social movements presented here as characteristic but not exclusive examples- prove that the interactive communication environment and the subsequent "democratisation" of communication provide the chance for the supporters of any marginal position (in terms of the ability to access the mainstream media) to connect with others, form communities, consolidate their argumentation, organise their communication strategy and disseminate their beliefs in order to claim their ground in the (digital) public sphere and through doing so to propagate their doctrines and try to influence wider publics.

These examples stand as characteristic of the "both-and" rationale (Beck 2009) that permeates the online world, especially in the age of Web 2.0+. The fusion of different kinds of media traditional and new ones in the interactive digital space creates a much more complicated context for human communication and politics, having both positive and negative attributes at the same time. Living in the age of "both-and" implies simultaneity, hybridity, pluralism, multiplicity, connectivity, networking, inclusiveness, cosmopolitanism, contingency, uncertainty and, maybe above all, ambivalence and doubt (Demertzis and Tsekeris 2018:4).

\section{Concluding remarks}

Our approach to the notion of post-truth, through consideration of conceptions of information management and propaganda, illustrates that post-truth can be understood as propaganda exercised mainly, but not exclusively, within and adapted to the contemporary, interactive, multi-dimensional, communication context. Post-truth is identical to propaganda, since it seeks to influence public opinion using specific, diachronically implemented, discursive practices. It can be located, predominantly, in public political -

\footnotetext{
${ }^{2}$ On the $9^{\text {th }}$ of November 2017, 500 "flat-Earthers" assembled in North Carolina for the first annual Flat Earth International Conference, while data from Google Trends shows that in the past two years, searches for "flat earth" have more than tripled (The Data Team 2017).
} 
though not necessarily coming from politicians - and journalistic discourse. Coincidentally, its recent scrutiny can be seen as emerging from specific political communication events which, for us, resonate strongly with the kind of political events that originally triggered significant research on propaganda, about a century ago.

Propaganda, particularly with respect to its exercise through social media and the internet, is intensely based on subjective interpretations of reality. Hence it may originate through a multiplicity of communicators within the new media communication milieu and it needs to stand its ground - if needed - against the immediate controls on "truthfulness" conducted on behalf of fact-checking organizations (Poynter 2018) and individuals. In this context, post-truth is a communication strategy that, at its core, remains identical to propaganda and - just like propaganda - seeks to adapt itself to the peculiarities and antagonisms of the new media communication environment, in order to retain its capacity for significant influence.

What this paper suggests, is that a thorough examination of propaganda should endeavour to remove any positive or negative connotation and focus on the actual construction and dissemination of a specific discursive strategy (Taylor 2003; Auerbach and Costronovo 2013), through the use of any specific discursive or non-discursive practices aimed at influencing various publics (either offline or online). Studying what Wittgenstein called 'language games' requires; firstly a focus on the interrogation of different discursive constructions of truth (Hodges 2017) and, secondly, a focus on their causes and aims, since propaganda is not a fragmented method, but rather a constant procedure designed for the continuous guidance of public opinion in line with the interests of the propagandists. Under this rationale, it seeks to create a specific context; a perception of reality through managed and disseminated information (Poulakidakos 2014).

The study of propaganda remains highly relevant and will continue to be a critical issue in the future. The very emergence of new terms such as 'post-truth' and 'fake news', even though they actually describe old phenomena, indicates the wide interest of societies in the study of public communication and propaganda strategies. We upload and watch, we read and post, we google and are spammed, becoming relays within and across these networks in ways that blur the distinction between the production and the consumption of information. To the extent that ordinary citizens are caught up by and occupy fields of mass persuasion, propaganda matters and will continue to matter (Auerbach and Castronovo 2013). We should not neglect, though, that despite the proliferation of newer technologies of knowledge, there still exist asymmetries in the ability to manage and disseminate information of public interest.

\section{References}

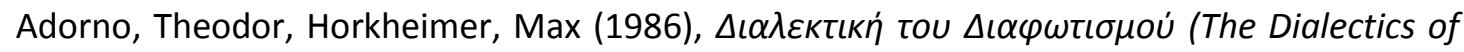
Enlightment), Athens: Ypsilon/Books.

Auerbach, Jonathan and Castronovo, Russ (eds.) (2013), The Oxford Handbook of Propaganda Studies, Oxford, New York: Oxford University Press.

Axford, Barrie (2011), 'Talk About a Revolution: Social Media and the MENA Uprisings, Globalizations, 8:5, pp. 681-686.

(2018), 'Mere connection? The transformative impact of new media in insurrectionary and usual politics', in Barrie Axford, Didem Buhari Gulmez and Seckin Baris 
Gulmez (eds.) Rethinking Ideology in the Age of Global Discontent, London and New York: Routledge.

Ball, James (2017), Post-truth. How bullshit conquered the world, London: Biteback Publishing.

Bauman, Zigmund (1997), Postmodernity and its discontents, Cambridge: Polity Press.

Beck, Ulrich (2009), World at Risk, Cambridge: Polity Press.

Bell, Daniel (1978), The Cultural Contradictions of Capitalism, New York: Basic Books.

Berghel, Hal (2017), 'Alt-News and Post-Truths in the "Fake News" Era', Computer, 50:4, pp. 110-114.

Bernays, Edward (1928), Propaganda, New York: H. Liveright.

Bratich, Jack, Zeljko (2004), 'Trust No One (on the Internet). The CIA-Crack-Contra Conspiracy Theory and Professional Journalism', Television and New Media, 5:2, pp. 109139.

Burr, Vivien (2006), An Introduction to Social Constructionism, London: Routledge.

Castells, Manuel (2000), The Rise of the Network Society, Oxford: Blackwell Publishing. (2004), The Network Society: A Cross-Cultural Perspective, Cheltenham: Edward

Elgar.

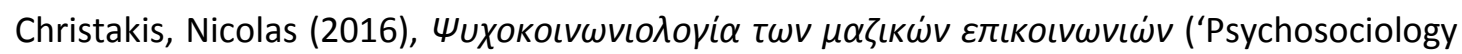
of mass communications'), Athens: Gutenberg.

Clarke, Steve (2007), 'Conspiracy Theories and the Internet: Controlled Demolition and Arrested Development', Episteme, 4, pp. 167-180.

Corner, John (2017), 'Fake news, post-truth and media-political change', Media, Culture and Society, 39:7, pp. 1100-1107.

Cox, Andrew M. (2013), 'Information in social practice: A practice approach to understanding information activities in personal photography', Journal of Information Science, 39:1, pp. 6172.

Cull Nicholas John, Culbert David Holbrook, Welch David (2003), Propaganda and Mass Persuasion, a Historical Encyclopedia from 1500 to present, Santa Barbara: ABC-CLIO Ltd.

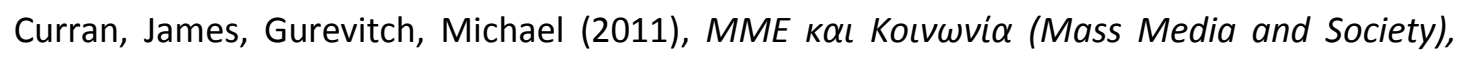
Athens: Patakis.

Curtis, Mark (2003), Web of Deceit: Britain's Real Role in the World, London: Vintage.

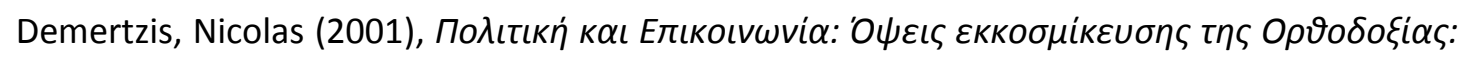

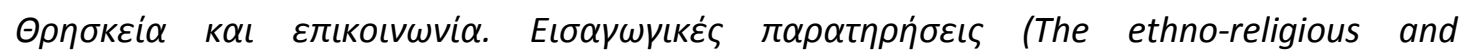
Communicative secularization of Orthodoxy), Science and Society, 5-6, pp. 83-101.

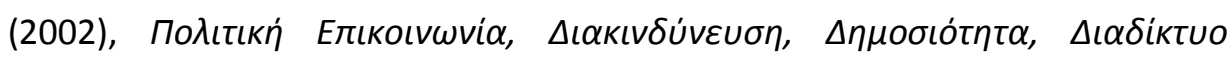
('Political Communication, Risk, Publicity, Internet'), Athens: Papazisis.

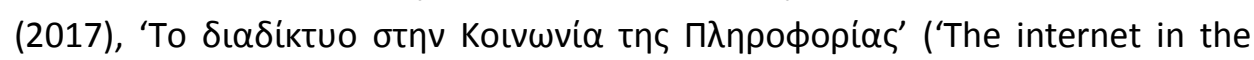

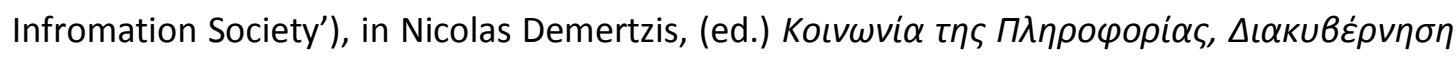

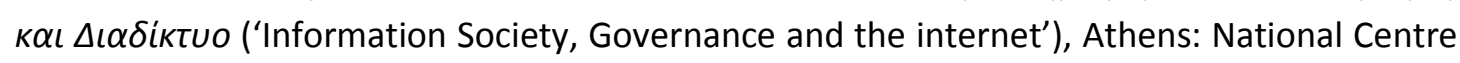
For Social Research.

Demertzis, Nicolas and Tsekeris, Charalambos (2018), 'Multifaceted European Public Sphere. Socio-Cultural Dynamics', Media@LSE Working Paper Series, 51, pp. 1-27.

Dylko, Ivan and McCluskey, Michael (2012), 'Media Effects in an Era of Rapid Technological Transformation: A Case of User-Generated Content and Political Participation', Communication Theory, 22, pp. 250-278. 
Ellul, Jaques (1973), Propaganda, the Formation of Men's Attitudes, New York: Vintage Books.

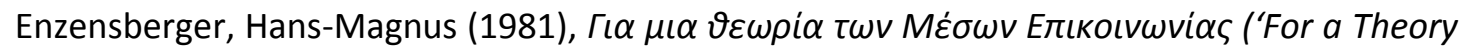
of Media of Communication'). Athens: Epikouros.

Flood, Alison (2016), 'Post-truth' named word of the year by Oxford Dictionaries', https://www.theguardian.com/books/2016/nov/15/post-truth-named-word-of-the-year-byoxford-dictionaries. Accessed on December 202017.

Fowler, Roger (2003), Language in the News. Discourse and Ideology in the Press, London: Routledge.

Fox, Jesse and Warber, Katie M. (2015), 'Queer Identity Management and Political SelfExpression on Social Networking Sites: A Co-Cultural Approach to the Spiral of Silence', Journal of Communication, 65, pp. 79-100.

Gerhards, Jürgen and Schäfer, Mike S. (2010), 'Is the internet a better public sphere? Comparing old and new media in the USA and Germany', Social Media \& Society, 12:1, pp. 143-160.

Gillmor, Dan (2004), We the Media. Grassroots Journalism by the People, for the People, Sebastopol CA: O' Rilley Media Inc.

Gleick, James (2011), The Information: a history, a theory, a flood, New York: Knopf Doubleday Publishing Group.

Habermas, Jurgen (1984), The Theory of Communicative Action, London: Beacon Press.

Hall, Stuart and Gieben Bram (eds.) (1992), Formations of Modernity, Cambridge: Polity Press.

Hanretty, Chris (2011), Public Broadcasting and Political Interference, London: Routledge.

Harsin, Jayson (2006), 'The rumour bomb: Theorising the convergence of new and old trends in mediated US politics', Southern Review: Communication, Politics \& Culture, 39:1, pp. 84110.

(2014), 'Public argument in the new media ecology: Implications of temporality, spatiality, and cognition', Journal of Argumentation in Context, 3:1, pp. 7-34.

(2015), 'Regimes of Posttruth, Postpolitics, and Attention Economies', Communication, Culture and Critique, 8:2, pp. 327-333.

Harvey, David (1990), The condition of postmodernity, Malden: Blackwell Publishing.

Hodges, Brian D. (2017), 'Rattling minds: the power of discourse analysis in a post-truth world', Medical Education, 51, pp. 235-245.

Hofseth, Anders (2017), 'Fake News, Propaganda, and Influence Operations - a guide to journalism in a new, and more chaotic media environment', https://reutersinstitute.politics.ox.ac.uk/risj-review/fake-news-propaganda-and-influenceoperations-guide-journalism-new-and-more-chaotic. Accessed on 23 December 2017.

Jowett, Garth and O'Donnell, Victoria (2015), Propaganda and Persuasion, $6^{\text {th }}$ edition, London: Sage.

Keyes, Ralph (2004), The Post-truth Era: Dishonesty and Deception in Contemporary Life, New York: St. Martin's Press.

Kumar, Deepa (2006), 'Media, War, and Propaganda: Strategies of Information Management During the 2003 Iraq War', Communication and Critical/Cultural Studies, 3:1, pp. 48-69. Kumar, Krishan (2005), From post-industrial to post-modern society, Oxford: Blackwell. Lash, Scott and Urry, John (1996), Economies of Signs and Space, London: Sage. 
Levinson, William (1999), An Introduction to Propaganda, Combat Forces Press: Washington. Lilleker, Darren (2017), 'Post-truth and how to combat fake news', http://darrenlilleker.blogspot.gr/. Accessed on 5 June 2017.

Lippmann, Walter (1927), The Phantom Public, New York: MacMillan.

Liu, Yu, Rui, Jian Raymond and Cui, Xi (2017), 'Are people willing to share their political opinions on Facebook? Exploring roles of self-presentational concern in spiral of silence', Computers in Human Behavior, 76, pp. 294-302.

Losee, Robert M. (1998), 'A Discipline Independent Definition of Information', Journal of the American Society for Information Science, 48:3, pp. 254-269.

Luhmann, Niklas (2000), The reality of the Mass Media. London: Polity Press.

Luo, Linfeng, Li, Min, Wang, Qing, Xue, Yibo, Liu, Chunyang and Wang, Zhenyu (2016), 'Spiral of Silence in Social Networks: A Data-driven Approach', 2016 IEEE/ACM International Conference on Advances in Social Networks Analysis and Mining (ASONAM), San Francisco CA, USA, 18-21 August 2016.

Marková, Ivana (2008), 'Persuasion and Propaganda. One or two processes? Persuasion, propaganda and rhetoric', Diogenes, 217, pp. 37-51.

Martin, Nora (2017), 'Journalism, the Pressures of Verification and Notions of Post-Truth in Civil Society', Cosmopolitan Civil Societies: An Interdisciplinary Journal, 9:2, pp. 41-55.

McComiskey, Bruce (2017), Post-truth rhetoric and composition, Colorado: Utah State University Press.

McNair, Brian (2006), Cultural Chaos. Journalism and Power in a Globalized World, London: Routledge.

McQuail, Denis (2010) McQuail's Mass Communication Theory, $6^{\text {th }}$ edition, Los Angeles, London, New Delhi, Singapore, Washington DC: Sage.

Miotto, Antonio (1953), Psicologia della Propaganda ('Psychology of Propaganda'), Florence: Editrice Universitaria.

Mitu, Bianca and Poulakidakos, Stamatis (eds.) (2016), Media Events: A critical contemporary approach, London: Palgrave-McMillan.

Miyata, Kakuko, Yamamoto, Hitoshi and Ogawa Yuki (2015), 'What Affects the Spiral of Silence and the Hard Core on Twitter? An Analysis of the Nuclear Power Issue in Japan', American Behavioral Scientist, 59:9, 1129-1141.

Nerone, John (2015), The media and public life: a history, Cambridge-UK, Malden-USA: Wiley.

Nimmo, Dan, D. and Sanders, Keith, R. (1981), Handbook of Political Communication, Beverly Hills-London: Sage Publications.

Noelle-Neumann, Elizabeth (1974), 'The Spiral of Silence. A theory of public opinion', Journal of Communication, 24:2, pp.43-51.

Oremus, Will (2016), 'Stop calling everything post-truth', http://www.slate.com/articles/technology/technology/2016/12/stop_calling_everything_fa ke_news.html. Accessed on 18 December 2017.

Pang, Natalie, Ho, Shirley S., Zhang, Alex M.R., Ko, Jeremy S.W., Low, W.X.and Tan Kay S.Y. (2016), 'Can spiral of silence and civility predict click speech on Facebook?', Computers in Human Behavior, 64, pp. 898-905. 
Pappas, Stephanie (2018), 'Flat Earth: What Fuels the Internet's Strangest Conspiracy Theory?', https://www.livescience.com/61655-flat-earth-conspiracy-theory.html. Accessed 25 July 2018.

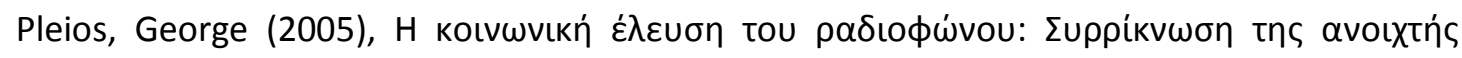

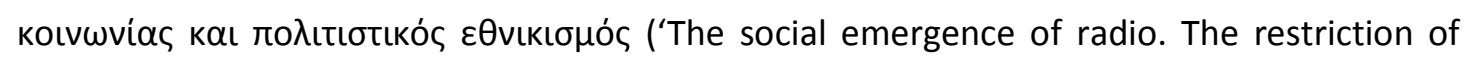
open society and cultural nationalism'), Communication Issues, 2, pp. 66-82.

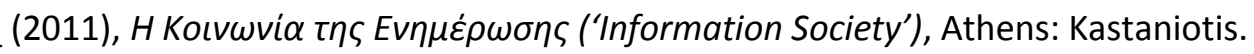

Porten-Cheé, Pablo and Eilders, Christiane (2014), 'Spiral of silence online: How online communication affects opinion climate perception and opinion expression regarding the climatechange debate', Studies in Communication Science, 15, pp. 143-150.

Poster, Mark (1990), The Mode of Information. Poststructuralism and Social Context, Cambridge: Polity Press.

(1995), The Second Media Age, Cambridge: Polity Press.

Postman, Neil (1985), Amusing Ourselves to Death: Public Discourse in the Age of Show Business, USA: Penguin.

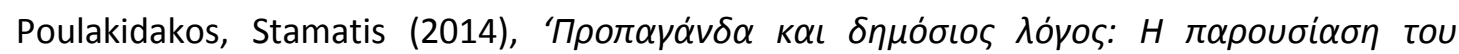

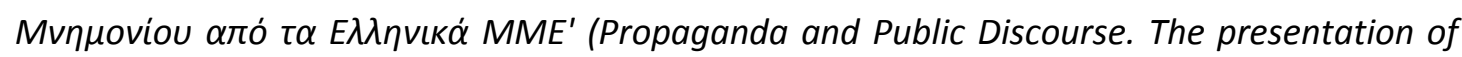
the MoU by the Greek Media), Athens: DaVinci Books.

Poulakidakos, Stamatis and Armenakis, Antonis (2014), 'Propaganda in Greek Public Discourse. Propaganda Scales in the presentation of the Greek MoU-bailout agreement of 2010', Revue des Sciences Politiques, 41, pp. 126-140.

Powell, Martin (2017), 'This is my (post) truth. Tell me yours', International Journal of Health Policy Management, 6:12, pp. 723-725.

Poynter Institute (2018), 'Fact-checking', https://www.poynter.org/channels/fact-checking. Accessed 22 March 2018.

Rabin-Havt, Ari and Media Matters for America (2016), Lies, Incorporated. The World of Post-truth Politics, New York: Anchor Books.

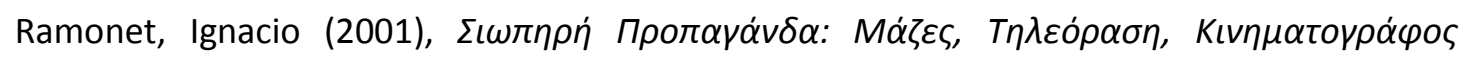
('Silent Propaganda: Masses, Television, Cinema'), Athens: Polis.

Roszak, Theodore (1986), The Cult of Information: The Folklore of Computers and the True Art of Thinking, Cambridge: Lutterworth Press.

Rowe, Sylvia and Alexander, Nick (2017), 'Food and nutrition science communications: behind the curtain', Nutrition Today, 52:3, pp. 151-154.

Schiller, Herbert I. (1984), Information and the Crisis Economy. Norwood, NJ: Ablex.

Severin, Werner J. and Tankard James W. Jr. (2000), Communication Theories: Origins, Methods and Uses in the Mass Media, New York: Longman.

Siegel, Pascale-Combelles (2005), 'Perception Management: IO's Stepchild?', Low Intensity Conflict \& Law Enforcement, 13:2, pp. 117- 134.

Snow, Nancy and Taylor Philip (eds.) (2009) Routledge handbook of Public Diplomacy. London: Routledge.

Soffer, Oren and Gordoni, Galit (2018), 'Opinion expression via user comments on news websites: analysis through the perspective of the spiral of silence', Information, Communication and Society, 21:3, pp. 388-433.

Soules, Marshall (2015), Media, Persuasion and Propaganda, Edinburgh: Edinburgh University Press. 
Speed, Ewan and Mannion, Russell (2017), 'The Rise of Post-truth Populism in Pluralist Liberal Democracies: Challenges for Health Policy', International Journal of Health Policy and Management, 6:5, pp. 249-251.

Sproule, J. Michael (1997), Propaganda and Democracy: The American Experience of Media and Mass Persuasion, New York: Cambridge University Press.

Stratford, Robert (2017), 'Post-truth, political ecology and education', Educational Philosophy and Theory, 49:6, pp. 586-587.

Taylor, Philip (2003), Munitions of the Mind: A History of Propaganda from the Ancient World to the Present Day, Manchester: Manchester University Press.

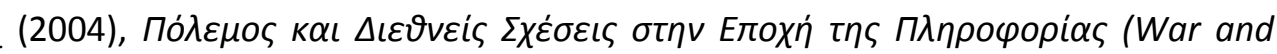
International Relations in the Information Age), Athina: Papazisis.

Terranova, Tiziana (2004), Network Culture, Politics for the Information Age, London: Pluto Press.

The Data Team (2018), 'America's flat-Earth movement appears to be growing', https://www.economist.com/graphic-detail/2017/11/28/americas-flat-earth-movementappears-to-be-growing. Accessed 25 July 2018.

The Economist (2016), 'Post-truth politics. Art of the lie', https://www.economist.com/news/leaders/21706525-politicians-have-always-lied-does-itmatter-if-they-leave-truth-behind-entirely-art. Accessed 21 December 2017.

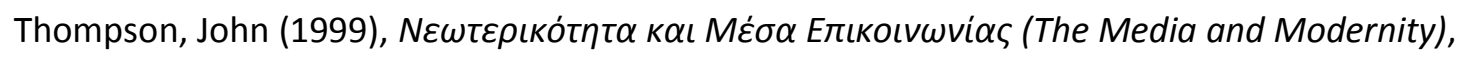
2nd edition, Athens: Papazisis.

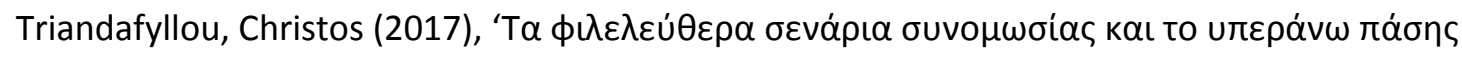
uпо廿ias post-truth' ('The liberal conspiracy scenarios and the above suspicion post-truth'), http://skra-punk.com/2017/04/02/ta-filelefthera-senaria-synomosias-ke-yperano-pasisypopsias-post-truth/. Accessed 21 December 2017.

Tunstall, Jeremy (2008), The Media were American: U.S. mass media in decline, New York: Oxford University Press.

Uberti, David (2017), 'Donald Trump killed the news cycle', https://www.cjr.org/criticism/donald-trump-news-cycle-slow-news-day.php. Accessed on December 102017.

van Prooijen, Jan-Willem and Douglas, Karen, M. (2017), 'Conspiracy theories as part of history: The role of societal crisis situations', Memory Studies, 10:3, pp. 323-333.

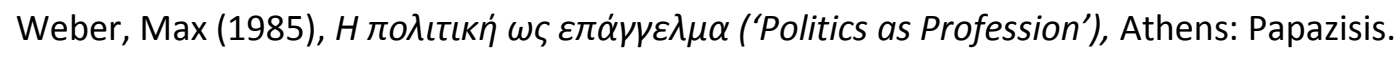

Webster, Frank (2006), Theories of the Information Society, $3^{\text {rd }}$ edition, London: Routledge.

Yenko, Athina (2018), 'The Flat Earth Movement Is Growing, Survey Reveals', https://www.techtimes.com/articles/224746/20180412/the-flat-earth-movement-is-

growing-survey-reveals.htm. Accessed 25 July 2018.

Zerbak, Thomas and Fawzi, Nayla (2017), 'Can online exemplars trigger a spiral of silence? Examining the effects of exemplar opinions on perceptions of public opinion and speaking out', New Media and Society, 19:7, pp. 1034-1051.

Zollman, Florian (2017), 'Bringing Propaganda Back into Media Studies', Critical Sociology, pp. 1-17. 